\title{
Comunicação: um grande desafio científico e político do século XXI
}

\begin{abstract}
RESUMO
0 texto trata da importância do estudo e da pesquisa da comunicação através de um vasto resumo de suas diferentes abordagens teóricas e correntes de pensamento. Distinguindo o seu valor normativo e funcional, o autor nos permite uma avaliação das técnicas de comunicação e do papel importante que elas desempenharam, ao longo da história até os dias de hoje, na formação da sociedade. Dessa forma, o texto nos leva a compreender o desenvolvimento do conhecimento da filosofia da comunicação em relação à filosofia política e a sua contribuição para o desenvolvimento da mesma.
\end{abstract}

\begin{abstract}
In this paper the author describes several approaches to the study of communications, showing the contribution they have brought about to a philosophy of communication related to political philosophy and to its development.
\end{abstract}

PALAVRAS-CHAVE

- Comunicação (Comunication)

- Filosofia da Técnica (Philosophy of technics)

- Filosofia Polítca (Political philosophy)
Mais de vinte anos de pesquisas pessoais ${ }^{2} \mathrm{e}$ de responsabilidades científicas ${ }^{3}$ me permitem confirmar essa hipótese tão raramente aceita: a comunicação é um grande desafio científico e político do século XXI. O triunfo das técnicas, aproximando os homens e a sociedade, obriga, efetivamente, um potente esforço de conhecimento, pois essa aproximação torna mais visíveis as diferenças culturais, sociais e religiosas, aumentando as dificuldades de intercompreensão. O fim das distâncias geográficas acentua o peso das dificuldades culturais e, portanto, a necessidade de uma real vontade para se tolerar mutuamente. As máquinas podem ser "on-line", os indivíduos e as sociedades não o serão jamais.

Essa reviravolta na ordem de importância entre o fim das distâncias geográficas e o crescimento das distâncias culturais é também uma aposta política, pois a informação e a comunicação não são somente processos técnicos; elas são também valores fundamentais de emancipação individual e coletiva desde o século XVIII. Elas estão, por exemplo, no centro do modelo ocidental atual que chamo de "a sociedade individualista de massa" e que deve gerar, simultaneamente, duas heranças contraditórias de nossa filosofia política: a liberdade do século XVIII e a igualdade do século XIX. A informação e a comunicação, portanto, ora são os valores centrais do Ocidente, ora o objeto de um progresso técnico, duplicado pelas apostas econômicas. Qual a relação que subsiste, hoje em dia, entre os sonhos de intercompreensão e a formidável reorganização da economia capitalista sob o nome de "sociedade da informação"?

\section{Teoria da comunicação e teoria da sociedade}

Em termos de comunicação faz-se necessário entende cinco fenômenos. A comunicação interpessoal; a comunicação mediatizada pelas técnicas clássicas ou novas; a comunicação política; a comunicação intercultural, assim
Dominique Wolton ${ }^{1}$

CNRS/França 
como os modelos de organização da sociedade através de valores, dos símbolos e das representações. Ou seja, o que permite aos indivíduos e às coletividades se representarem e entrarem em relação uns com os outros e agirem sobre o mundo.

Através da comunicação, joga-se em definitivo a relação de cada um de nós com o mundo. Assim, não há sociedade sem comunicação, a fortiori no modelo democrático que coloca o princípio de liberdade e igualdade de seus sujeitos nas nossas relações mútuas. A comunicação se torna, então, o horizonte de toda sociedade democrática com a necessidade de resolver os seus objetivos contraditórios: assegurar a comunicação entre os indivíduos livres e assumir, ainda assim, a aspiração à igualdade, que é o horizonte das sociedades democráticas. Assegurar, também, um mínimo de cooperação respeitosa das diferenças culturais e políticas no seio da comunidade internacional, no momento em que as maiores indústrias do mundo - as indústrias de comunicação - vêem a Terra como sendo um só grande mercado.

Entre os valores da comunicação, as técnicas da comunicação e a economia da comunicação tudo se mistura e se confunde. Afinal, entre valor e economia as técnicas parecem fazer "naturalmente" o laço. Do telefone ao rádio, da televisão à internet, eles "encarnam" o duplo ideal de liberdade e igualdade da informação e da comunicação. A técnica parece ter se tornado o braço armado do ideal ocidental, mesmo se essas técnicas são simultaneamente inseparáveis do crescimento mundial. Quando nós falamos do village global, trata-se de um ideal de comunicação sob o plano mundial ou da infra-estrutura da primeira indústria no mundo, aquela da informação e da comunicação? A sociedade da informação é o ideal de uma sociedade democrática na escala do mundo ou invólucro ideológico da economia mundial da informação? Dizendo de outra maneira, a onipresença da informação e da comunicação, em nível mundial, não é suficiente para assegurar uma sociedade justa, igualitária e comunicativa. O e-liberdade é uma formidável garantia ao enegócio, e os grandes grupos de comunicação mundial devem ser os primeiros a se gabar dos méritos da e-democracia ou do etraining, dos quais serão, além do mais, os grandes beneficiários econômicos. Nadamos em plena confusão. Acrescente aliança entre o ideal da comunicação, a performance das técnicas e a realidade da economia obriga a um formidável trabalho de conhecimento para distinguir as apostas, criar os conhecimentos.

É esse duplo estatuto da comunicação, ora como valor fundamental, ora como instrumento de crescimento econômico, que a faz uma das maiores apostas do futuro. Isso requer um trabalho crítico fundamental para separar, nessa onda de técnicas, discursos, serviços, ideologias, o que nos remete a um ideal de comunicação e de intercompreensão do que nos remete a uma realidade da nova etapa da história da economia, "a economia da informação". A aposta científica e de conhecimento é mesmo anterior à aposta política, pois os conhecimentos ajudam a fazer a triagem entre os discursos e as promessas.

Com que instrumento operaramos essa triagem? Talvez com o mais simples, aquele que vem da etimologia. A comunicação tem duas raízes. A primeira liga comunicação e divisão, compreensão e respeito ao outro. É o ideal da comunicação em nível individual ou coletivo. Isso que eu chamo de dimensão normativa serve de referência tanto sob o plano da comunicação intersubjetiva quanto das técnicas ou das sociedades. A segunda, mais recente e reforçada pelas técnicas de comunicação, cuja primeira entre elas é a imprensa, insiste na idéia de transmissão, com a hipótese, durante muito tempo verdadeira, de que quanto mais se tinha informações, mais se tinha comunicação. Hoje, a onipresença das técnicas e o volume dos fluxos de informações nos obrigam a nos darmos conta de que não é mais suficiente a difusão de um grande número de informações, nem mesmo assegurar a interação, para aumentar a comunicação entre indivíduos ou coletividades. Essa segunda dimensão, que eu chamo funcional, insiste, evidentemente, nas performances, sem, portanto, assegurar forçosamente uma intercompreensão.

Difundir um grande número de informações e organizar suas interações não significa ter mais a comunicar. A comunicação objetiva o tecnicismo, ou ainda a ideologia técnica que confunde performance e comunicação humana e social. O tecnicismo é a idéia simples preconizada pelas indústrias da informação e da comunicação, segundo a qual quanto mais os indivíduos e as sociedades são equipadas, "aparelhadas", mais a comunicação normativa é assegurada. O tecnicismo consiste, simplesmente, em estabelecer uma 
continuidade entre sistema técnico e realidade social. É por isso que toda reflexão teórica sobre a comunicação passa hoje por uma reflexão crítica sobre as técnicas, não para criticar o papel delas, mas para relativizar seus lugares. Dizendo de outra maneira, socializar a técnica para evitar a tecnização da sociedade. Fazer humanistas internautas e não internautas esquizofrênicos. Evitar que as técnicas se esquivem da interatividade. Evitar as "solidões interativas". Aliás, esse procedimento reata com a tradição da filosofia e da história das ciências e das técnicas que sempre insistiu na descontinuidade entre sistema técnico e sociedade. Certamente, as técnicas influenciam as sociedades, mas dentro de uma interatividade complicada, os papéis dos modelos culturais e sociais estando freqüentemente também menos fortes. $E$ esse papel dos modelos culturais e sociais é ainda maior quando se trata das técnicas da comunicação.

\section{Comunicação normativa ou funcional: dividir ou transmitir?}

A aposta científica da comunicação consiste, então, em ora distinguir dentro de cada atividade de comunicação o normativo do funcional, ora socializar as técnicas para evitar a tecnização da comunicação.

Socializar é ver o laço existente em cada época entre um modelo social e cultural da comunicação e os sistemas técnicos. É fazendo esse trabalho que podemos situar a cada vez as apostas da comunicação em relação aos modelos sociais, políticos e culturais dominantes. Aliás, a esse propósito, não podemos opor a comunicação humana que seria normativa à comunicação técnica que seria funcional. Não pode haver tanta comunicação normativa por intermédio da técnica como, desde há muito tempo, a imprensa, a livraria, o rádio e a televisão o provam; não pode ter comunicação funcional nas relações humanas diretas, como vemos em muitas situações sociais em empresas ou em família, ou na vida na cidade ou no campo.

A oposição, fundamental a manter em cada época, entre o normativo e o funcional, não recorta necessariamente a oposição entre comunicação humana e comunicação técnica. Isso voltaria a isolar a problemática técnica, embora o interesse, do meu ponto de vista, de uma reflexão teórica sobre o estatuto da comunicação dentro da sociedade, é o de ver, desde o século XVI, como se ligaram em cada época um projeto cultural e social, a comunicação e as técnicas.

As grandes técnicas da comunicação adquiriram $\mathrm{o}$ seu sentido apenas porque encontraram o eco de um projeto cultural e social da comunicação. E é esse laço entre sistema técnico e modelo de comunicação que faz, segundo o que penso, o interesse de uma reflexão sobre a comunicação há três séculos. Toda a reflexão sobre o ideal da comunicação, desde o século XVII, ligada à liberdade de consciência, depois à liberdade individual, depois à liberdade política e, enfim, à idéia de igualdade, foi acompanhada de uma batalha sobre o sentido a ser dado aos sistemas técnicos de comunicação. Dizendo de outra maneira, se as técnicas de comunicação tiveram um papel essencial na livraria, na imprensa e no telefone, depois no rádio e na televisão, é porque, cada vez mais, elas se inseriam em um dos capítulos dessa longa batalha cultural e política da comunicação.

A livraria e a imprensa são inseparáveis dos modelos da democracia liberal, como o rádio e a televisão são da democracia de massa. A aposta das técnicas atuais de comunicação é saber como elas se inscrevem dentro do duplo ideal de nossas sociedades contemporâneas, "a sociedade individualista de massa", com suas duplas referências à liberdade individual e à igualdade social. Cada uma das técnicas existentes é mais ou menos apropriada a uma das duas escalas de comunicação. E todo interesse e dificuldade da internet, progresso técnico decisivo, é saber se ela redireciona ou não essa problemática dos laços entre essas duas escalas da comunicação. No momento, a internet reforça mais as possibilidades de comunicação individual do que traz uma mudança em relação à outra dimensão da comunicação, melhor tratada pelo rádio e pela televisão e que está ligada ao modelo da democracia de massa, ou seja, à gestão da heterogeneidade social e cultural.

É por isso que, de um ponto de vista da teoria da comunicação, eu digo que o sistema técnico da internet, atualmente, não apresenta um avanço da problemática atual da comunicação: religar os indivíduos sob uma base de interesse comum e, entretanto, assegurar um mínimo de coesão social. Pois tal é a esperança de nossa teoria democrática 
da comunicação: ora permitir a comunicação intersubjetiva, ora a comunicação social. É por isso que na aposta da comunicação, como eu digo freqüentemente, é menor a gestão do parecido do que a gestão das diferenças. É menor a capacidade de colocar em relação os indivíduos e as comunidades que têm interesses comuns do que a capacidade de organizar a coabitação entre comunidades e sociedades heterogêneas. É menor a performance de instrumentos do que a filosofia da comunicação que os sustenta. Depois de tudo, são os homens que inventam os modelos de comunicação, em princípio situados nas suas cabeças, antes de o serem nos instrumentos. E, aliás, a história das técnicas, compreendendo a comunicação, está repleta de instrumentos que nunca tiveram, finalmente, vida social durável, simplesmente porque eles não correspondiam a uma aposta social e cultural.

Lembrar a proeminência da dimensão cultural e social na comunicação é fundamental hoje em dia, onde o progresso técnico, considerável nesse setor, pode fazer crer que a performance técnica é a origem da mutação de modelos culturais da comunicação. As técnicas têm, evidentemente, um real impacto sobre os modelos culturais, assim como sobre a organização social da comunicação, mas, dentro da ordem de análise, elas não são as primeiras. Ou, mais precisamente na interação técnica, cultura e sociedade, no que diz respeito à comunicação, são os modelos culturais que têm o papel essencial. São as utopias da comunicação que dão seus sentidos aos instrumentos, mesmo se esses, através das mudanças que elesinduzem, têm evidentemente um impacto sobre os modelos culturais e sociais da comunicação.

\section{As ciências da comunicação; entre técnica e política}

Teremos compreendido a aposta em matéria de teoria da comunicação em seu laço com uma teoria política. Esse laço é radicalmente diferente se optarmos, finalmente, por uma filosofia humanista da comunicação ou por uma filosofia técnica. Tudo nos estimula, hoje, a fazer prevalecer a segunda. É nisso, finalmente, que as apostas do conhecimento e da política estão ligadas, concernindo uma reflexão sobre o estatuto da comunicação nas nossas sociedades; reflexão que, desde há um pouco mais de meio século, pariu as ciências da comunicação.

Não existe uma ciência da comunicação, porque a comunicação diz respeito a várias disciplinas. A comunicação é um objeto de conhecimento interdisciplinar, no cruzamento das disciplinas tradicionais e dos saberes recentes, ligados à expansão da comunicação e das técnicas do mesmo nome. Dez disciplinas a estruturam: Filosofia - Antropologia - Sociologia - Ciências Políticas - Lingüística - Direito Economia - História - Psicologia - Geografia.

Aliás, a prova de que esse domínio temainda dificuldade de ser legítimo é vista no fato de que a história das pesquisas sobre comunicação na França não é conhecida, ao contrário do que existe em outros países. Podemos, no entanto, distinguir quatro etapas:

1) A primeira vai até os anos de 1960. Ela se consagra, principalmente, ao estudo da imprensa escrita, em torno de alguns centros universitários, como o Institut Français de Presse, em Paris, que é o mais antigo centro de pesquisa universitária sobre a comunicação, fundado em 1938 por J. Stoetzel, e o Centre de R. Escarpit, em Bordeaux, fundado no final dos anos de 1950. O rádio não foi, infelizmente, objeto de grande curiosidade teórica. A comunicação, portanto, constituinte maior da modernidade, é ausente dessa interrogação sobre a forma de sociedade no após-guerra, exceto em relação a alguns trabalhos sobre a publicidade nascente. Os estudos literários a ignoram. A lingüística também.

2) O segundo período vai dos anos de 1960 a 1975. É o verdadeiro começo dos estudos, não sobre a comunicação, que não interessavam, mas sobre as mídias principalmente. A ausência de tradições francesas, nesses domínios, empurra os universitários a se voltarem para os países anglo-saxões, onde existem trabalhos de pesquisa. Faz-se necessário citar aqui os nomes de G. Friedmann, J. Cazeneuve, E. Morin, R. Barthes, O. Burgelin e Paul-Henri Chombart de Lauwe. G. Friedmann, que muito já tinha trabalhado para o desenvolvimento dasociologia industrial, introduziu a tradição americana de pesquisas sobre as mídias de massa. A maioria das questões de hoje sobre a influência das mídias, a sociedade de comunicação, o problema do nível cultural, a cultura de elite, o fim do livro, a ideologia americana, a imagem..., foram já colocadas. 
Maio de 68 vai brutalmente colocar fim nesse princípio de estudo das mídias e da comunicação. O papel essencial que teve o CEMAS (criado em 1960), graças a G. Friedmann, E. Morin e R. Barthes na Ecole de Hautes Études, é retrospectivamente destacado. Mesmo a problemática da recepção e do público já estava presente. Em oposição, o rádio, em uma quase indiferença intelectual, viveu seu apogeu... Essa técnica, simples, leve, pouco onerosa, aparecera, aliás, no fim do século como a grande revolução do século XX.

3) A década seguinte (1975-1985) é, finalmente, aquela do contra-senso. Em relação à questão lancinante da influência das mídias, a causa parece definitivamente entendida. Maio de 68 tendo passado por aqui, o que houve tão-somente foi a questão da dominação, da alienação, da ideologia dominante. A Escola de Frankfurt triunfa com as figuras emblemáticas de H. Marcuse, e T. Adorno. Sobre o plano econômico, as teorias sobre o imperialismo cultural americano confirmam definitivamente o fato de que as mídias pertencem aos "aparelhos ideológicos". O debate apaixonado, violento, impresso de má-fé de uma parte e de outra "em torno da nova ordem mundial da informação", aconteceu pela Unesco, interposto a partir do parecer Mac Bride (1980). A informação mais que a comunicação, aliás, ilustra, há trinta anos, uma das formas essenciais do desequilíbrio Norte/Sul. Simultaneamente, aparece um outro discurso ligado às novas técnicas de comunicação. Aqui tudo é positivo! Atendemos muitas promessas da televisão a cabo do Canadá e dos Estados Unidos, que devem permitir a correção dos estragos da televisão de massa. As perspectivas de individualização do cabo, depois da informática, confirmam a abertura de uma outra história da comunicação. Paradoxalmente, essas inovações, inseparáveis das lógicas industriais, são tanto louvadas quanto é condenada a televisão de massa. Encontramos o velho afrontamento entre a atração pela lógica individual e a desconfiança em relação ao coletivo. É nessa época, sem dúvida, que nasce a ideologia técnica ligada aos serviços individualizados; esquecidos os interesses, as lógicas econômicas, os modelos culturais, a alienação. Tudo se torna "livre", graças às novas técnicas. Reencontramos, hoje, vinte anos depois, com as auto-estradas da informação, a internet, a democracia eletrônica, a teleeducação, os mesmos argumentos.
4) O quarto período começa em 1985. É o período da abertura intelectual. No domínio das pesquisas, assistimos a uma certa aproximação entre posições opostas. Os detentores de uma abordagem crítica do tipo marxista reconhecem, progressivamente, que o público é mais inteligente do que, ele parece e que apesar das dominações culturais e ideológicas as mídias não têm essa influência tão temida. O público aprendeu a "jogar" com as mídias. Os trabalhos sobre a história da imprensa, do telefone, do rádio e da televisão confortam a mudança de atitude, no sentido de que esses trabalhos valorizam a existência, em cada época, de uma autonomia relativa dos comportamentos sociais e culturais em relação a essas técnicas. Redescobrimos a importância do contexto sociocultural, simbolizado pelos cultural studies que insistem mais na interação entre técnicas, modelo e identidades culturais. Ao contrário, os detentores de uma abordagem empírica crítica, aos quais os acontecimentos deram razão, são obrigados a reconhecer, principalmente, que a extraordinária expansão das indústrias da comunicação obscurece a compreensão das relações entre comunicação e sociedade.

A filosofia política, reencontrando, finalmente, um interesse pela democracia pluralista, descobre os conceitos de espaço público e da problemática de argumentação, logo, da questão da intercompreensão. Damonos conta, enfim, que existem somente as mensagens eas confidências. Além disso, tem os indivíduos e as sociedades que constroem trocas bem complicadas. Em suma, a comunicação começa lentamente a se tornar uma questão teórica "digna". Os intelectuais observam, vagarosamente, que existem receptores que têm um papel central e que, quanto mais existem mensagens, mais eles filtram e têm um papel ativo bem distante da "passividade", da qual falamos durante muito tempo. Bem lentamente, muito lentamente em consideração às apostas políticas, a comunicação começa a se tornar uma questão teórica e prática essencial.

\section{De duas a quatro correntes de pesquisa}

$\mathrm{Na}$ realidade, em trinta anos, o campo da pesquisa se diversificou, passando de duas a quatro correntes. As duas primeiras opunham os empiristas-críticos aos críticos, a propósito de uma análise divergente sobre o lugar 
da comunicação na sociedade e sobre a capacidade crítica dos indivíduos. Duas novas abordagens apareceram, uma hypostasiant às novas técnicas, outra desconfiada em relação às problemáticas da comunicação, as duas últimas encontrando um eco bem favorável junto às elites culturais.

Por outro lado, um movimento de interesse real partiu "da base", ou seja, dos estudantes. $\mathrm{Na}$ década de 1980-1990, vemos multiplicar os DEAe os Terceiros ciclos3 em sociologia, antropologia, história, ciência política, ciência da informação e da comunicação. O nascimento desse público acadêmico dará origem a trabalhos de pesquisa. Uma primeira estruturação foi feita com a criação da ASFIC (Association française des sciences de l'information) em 1986. Ao contrário, um parâmetro praticamente não foi modificado em trinta anos: a demanda social continua fraca. Existe uma demanda de estudos ligada à expansão das indústrias, mas não a uma demanda de pesquisa. Enfim, depois de um vazio da informação na imprensa até os anos de 1980, em relação à comunicação, assistimos, ao contrário, desde a uma abundância de informações até a criação de emissões de rádio e de televisão, mais ou menos narcisistas, tendo as mídias, a publicidade e a comunicação como objeto. Isso resultou em um crescimento do nível de informação do público, ao mesmo tempo que em uma desproporção. As multimídias, internet... são objeto de uma exploração incessante, sem nenhuma abordagem crítica, o que virá, provavelmente, de uma extensão do público estudantil.

Para resumir esta evocação rápida de uma história das ciências da comunicação na França, poderíamos distinguir cinco fatores:

1. Em princípio, uma mudança radical do contexto em vinte anos. Nos anos de 1960, não tinha meio intelectual trabalhando sobre a comunicação, e a França estava atrasada em relação aos Estados Unidos, à Inglaterra, à Alemanha. Trinta anos depois, essa comunidade existe, mesmo ela sendo ainda fraca, necessitando, permanentemente, de um trabalho interdisciplinar, sempre difícil. Peguemos o exemplo das revistas. Nos anos de 1960, somente Communications e Communication et langage existiam realmente e durante trinta anos quase não teve criação de revistas. Acontece que, desde os anos de 1990, ao contrário, assistimos na França a uma quase explosão de revistas, como, aliás, na Europa, com destaque para o nascimento da Hermès, Réseaux, Quaderni, MEl, European Journal of Communication, Les Cahiers de médiologie, etc.

2. Um interesse crescente, mas acompanhado de verdadeiras dificuldades que dizem respeito à questão da comunicação. A comunicação não é nem uma disciplina nem uma teoria; é um cruzamento teórico. Vimos que ela se construiu com o cruzamento de aproximadamente dez disciplinas, o que explicaria uma certa dificuldade intelectual de conceituação. É criando instrumentos teóricos, conceitos, por exemplo, em torno do espaço público, da comunicação política, da argumentação, da opinião pública, da recepção, das utilizações, das interações, da comunicação intercultural...que chegaremos a escapar desta "tirania da comunicação".

3. A abordagem ideológica mudou de forma em trinta anos. Ontem, os adversários da comunicação eram, essencialmente, os marxistas, que conduziam uma luta dupla: ideológica, contra os mecanismos de dominação existentes na comunicação internacional audiovisual, e econômica, para denunciar o peso das indústrias culturais. Hoje, a corrente dominante é outra; é a ideologia tecnicista, aquela das indústrias, que exaltava "a sociedade da informação e da comunicação", que emergiria, finalmente, nos televisores e nos computadores. Amanhã, "tudo vai mudar" com a comunicação interativa; mesmo se isso já havia sido prometido há trinta anos, com a chegada da televisão comunitária a cabo, depois os computadores, as primeiras redes...

4. Aexplosão do mercado da comunicaçãoA desmedida está em tudo: 30 canais a domicílio parecem um mínimo, 50 alguma coisa de razoável, 100 a 120, o sinal do progresso... Sem falar nas promessas de interconexão com as redes. A comunicação se tornou um dos símbolos mais fortes da modernidade. É, aliás, o sucesso dessas técnicas que explica a amplitude dessa ideologia da comunicação, que se apóia certamente sobre as performances técnicas, mas, provavelmente, tanto mais sobre a crise dos três outros grandes valores que dominaram o século XX: a ciência; a religião; a política.

5. A diferença entre estudos e pesquisas. Ontem, as pesquisas do mundo acadêmico eram o único modo de acesso ao conhecimento de um setor vital, mas ignorado. Hoje, a demanda de conhecimento é sempre tão fraca, mas o fenômeno é mascarado pela abundância 
de informações existentes nos mercados, nas estratégias do ator, nas reestruturações econômicas, nas prospectivas técnicas, nos novos serviços e suas experimentações. Os estudos comandados pelos atores e pelos poderes públicos são suficientes.

\section{Os domínios dos conhecimentos}

Do ponto de vista das pesquisas, podemos, portanto, em vinte anos, nomear os domínios sobre os quais progressos foram feitos.

1. Comunicação e sociedade:

Comunicação institucional; história da imprensa e das técnicas de comunicação; ciências, culturas e comunicação; memória coletiva e história da comunicação; direito e economia da informação e da comunicação; história e memória sociais; o estatuto da imagem; a publicidade.

2. Mídias e democracia:

Os discursos políticos e as suas expressões: mediação e mediatização; mídias, crises e conflitos; evolução dos sistemas audiovisuais e das instituições de regulação; a emergência das novas técnicas de comunicação.

3. Comunicação e política:

Características e funcionamento do espaço público; opinião pública e comunicação política; discurso e práticas dos atores; contextos de emissão e de recepção das mensagens políticas no espaço público; informação e ação; as novas relações entre espaço público e espaço privado.

4. Estratégias de comunicação:

A modificação dos espaços-tempo; onstrução e expressão das opiniões; recepção das mensagens e comportamentos dos públicos; estratégias argumentativas e construção da realidade; construção, interação e interpretações; representações individuais e coletivas; comunicação interpessoal e comunicação a distância; as diferentes formas de comunicação interculturais; falas, gestos, imagens: a diversidade dos modos de comunicação.

5. A Europa e a comunicação intercultural:

Estereótipos e representações; identidade e comunicação; mídias e espaços nacionais; internacionalização da comunicação: apostas políticas, econômicas, institucionais e culturais; a União Européia e as fronteiras da Europa do Sul e do Leste; as dificuldades da comunicação intercultural: desigualdades sociais e choques de culturas; o conflito entre as indústrias de comunicação e a aposta da diversidade cultural.

\section{6}

\section{Quatro posições teóricas}

Parece-me que as posições teóricas, freqüentemente contraditórias, estruturam o campo da pesquisa, podendo ser agrupadas em quatro posições, resultado do crescimento de dois eixos. O primeiro diz respeito à ligação entre técnica e valor no domínio da comunicação. 0 segundo diz respeito aos graus de abertura e de fechamento que se fazem da sociedade.

No que se refere à comunicação, a oposição se dá entre os trabalhos que privilegiam uma abordagem técnica da comunicação em relação àqueles que privilegiam uma abordagem em termos de valor.

No que se refere à sociedade, a oposição se dá entre os trabalhos que privilegiam uma visão aberta da sociedade em relação aqueles que insistem ainda no tema do controle social e da dominação.

É, finalmente, por um lado, a ligação entre a técnica e o valor na comunicação e, por outro, a visão mais ou menos fechada da sociedade, que são os dois eixos em relação aos quais se distribuem os trabalhos sobre a comunicação. É, então, a relação comunicação - sociedade que se constitui no fator discriminante. Uma visão da informação e da comunicação revela sempre uma teoria implícita ou explícita da sociedade. Não há posição "natural" na comunicação, como também na imagem, na recepção, na televisão, nas novas técnicas, na comunicação intercultural... E cada uma dessas visões nos remete, finalmente, a uma concepção da comunicação e da sociedade. Podemos, então, colocar as seguintes questões em todo discurso técnico, acadêmico, político a propósito da comunicação: Quais são os pressupostos? De onde fala aquele que fala tão "naturalmente" da comunicação? Qual é a sua visão implícita da sociedade? Como essa influencia a sua concepção da comunicação?

Essas quatro posições se encontram, além da pesquisa, na imprensa, nos atores ou nos homens políticos. Lendo os artigos da imprensa ou escutando tal ator econômico ou político intervindo sobre o campo da comunicação podemos compreender em qual dessas posições um discurso se anexa.

1. A primeira corrente: os aduladores

Essa corrente, muito otimista em relação à 
sociedade assim como em relação às técnicas, agrupa aqueles que vêem nas rupturas técnicas a emergência de uma nova sociedade, mais democrática, mais relacional e interativa. Aqui se trata quase de uma "crença". Essa postura é onipresente nas mídias, nos jornais, nos trabalhos previsíveis. Aqui tudo ou quase tudo é "positivo". As "resistências" das sociedades são identificadas a um "medo de mudanças" e a arcaísmos.

Alógica econômica é o braço armado dessa revolução mundial que permitirá "redesenhar" as relações Norte/Sul. A educação, sendo um dos complementos dessa revolução da comunicação, permitirá aos países saltar uma etapa da sociedade industrializada para chegar diretamente na "sociedade da informação".

2. A segunda corrente: os críticos

Eles denunciam as derivas das indústrias da comunicação em nível mundial e o impacto geral das técnicas sobre as relações sociais. Os novos serviços não mudam nada e se constituem nas "camisas do amanhã". No entanto, uma luta pode ser empreendida para liberar as sociedades dessa influência tanto ideológica quanto econômica, técnica e política. Sobre o plano internacional, as ideologias da sociedade da informação são os álibis de uma nova divisão internacional do trabalho que reforça a dominação do Norte sobre o Sul.

3. A terceira corrente: os empiristas-críticos

É a idéia de uma margem de manobra nas relações entre comunicação e sociedade que predomina aqui. A comunicação é um valor antes de ser uma técnica e é, em nome dessa referência normativa, que é possível, no diaa-dia, levantar as contradições entre os ideais da comunicação e a realidade das indústrias da comunicação. A inteligência do público é a guardiã dessa dualidade da comunicação; ela é a simetria da inteligência do cidadão no modelo democrático. Aqui, a idéia de regulamentação é capital, como a de análise crítica.

4. A quarta corrente: os niilistas

Manifestam uma dupla desconfiança a propósito da sociedade e do Homem. Por outro lado, segundo os autores, os niilistas mais ou menos céticos dividem com os aduladores uma forte crença na potência das técnicas, mas de maneira simétrica. Para eles, além do mais, os atores são otários. Somente uma minoria, através de sua cultura, é capaz de denunciar as armadilhas e as ilusões dessa comunicação. A perspectiva é freqüentemente elitista.
7 Conclusão: as duas filosofias, política e técnica da comunicação

Desenvolver conhecimentos, logo pesquisas, no domínio da comunicação é uma aposta central por cinco razões:

1) A comunicação é, provavelmente, um dos setores da realidade que sofreu os maiores transtornos em cinqüenta anos. Basta pensar sobre o "antes" do telefone, do rádio, da televisão, da informática e a realidade de hoje. Mas se tratam de transtornos produzidos sem a existência de uma grande cultura científica, porque, ontem, a informação e a comunicação não se constituíam em um domínio legítimo e valorizado. O "atraso" se dá, então, mais do lado da teoria e da reflexão do que das técnicas e da economia.

2) A comunicação se torna uma grande aposta do século XX, tão importante quanto a ciência, a defesa, a educação, a saúde. O esforço de produção de conhecimentos deve, então, acompanhar a medida dessa importância econômica, social e cultural, tanto no plano das nações quanto naquele essencial para o amanhã, de respeito à diversidade cultural. Com a informação e a comunicação, tocamos as infra-estruturas mentais dos indivíduos e das coletividades.

3) Desenvolver os conhecimentos é também um meio de preservar a comunicação como valor característico da cultura ocidental e da democracia, no momento em que essa é compreendida e com sucesso por todos os interesses. Nada garante, no momento em que a comunicação se torna uma indústria mundial em plena expansão, que ela continuará ligada aos valores que a sustentam. Ela pode se tornar mesmo um fator de dominação e de desigualdade entre o Norte e o Sul, longe dos ideais de divisão e de emancipação que vimos nascer no Ocidente.

4) Desenvolver conhecimentos é agir, ao longo do tempo, para relativizar as promessas das "novas" técnicas; não reduzir a comunicação às técnicas; desenvolver trabalhos teóricos; favorecer o nascimento de uma comunidade científica. Finalmente, esse é um dos meios para guardar um pouco de distância em relação à sedução das técnicas e à pressão dos atores.

5) O risco amanhã? A marginalização dos pesquisadores e universitários em proveito dos "experts" e "conselheiros" de todo gênero, cujos discursos serão sempre mais sedutores, pois 
são diretamente ligados às realidades. Desde então, a comunicação se tornou uma indústria, a lógica dos interesses domina aquela dos valores. Tanto que não existe uma crise da comunicação, a demanda do conhecimento corre o risco de continuar fraca. Mais uma razão para desenvolvê-la no seio da universidade e do CNRS.

Deixaremos aberto o debate, apenas esboçado, sobre as duas filosofias da comunicação: dividir ou transmitir? A filosofia política insiste sobre o ideal de intercompreensão entre os homens e a sociedade. A filosofia técnica é sensível aos progressos que permitem a transmissão e a interatividade cada vez mais rápidas das informações e das comunicações de toda natureza. De um lado, a lentidão e as dificuldades a se compreender. De outro, a rapidez técnica. No meio, as promessas da economia, mais disposta a oscilar do lado de uma lógica técnica do que de uma lógica humanista.

Qual será o papel dos conhecimentos? Faz-se necessário distinguir, nas promessas, discursos, realizações, o que remete a essa filosofia política da comunicação do que remete a essa filosofia técnica. Essas duas filosofias não recortam forçosamente, como eu expliquei anteriormente, a oposição entre comunicação normativa e comunicação funcional, o que mostra a complexidade das relações entre comunicação e sociedade. É possível, efetivamente, ter uma comunicação normativa tanto na filosofia política quanto na filosofia técnica da comunicação. Ao contrário, a dimensão funcional pode ser encontrada tanto na abordagem política como técnica da comunicação. Em todo caso, distinguir duas visões, técnica e política da comunicação, permite colocar em perspectiva as apostas ligadas à economia da comunicação e aos projetos sociais, culturais e educativos, que são os seus prolongamentos. Em todo caso, distinguir e diferenciar os problemas de natureza diversa não é, finalmente, o que caracteriza o ato do conhecimento?

\section{Notas}

1 Artigo publicado originalmente em L'Année sociologique, 2001,51, n², p. 309-326. Texto traduzido por Cristiane Freitas.

2 Ver, especialmente, Les réseaux pensant: télécommunication et société (1978) ; L'information demain. De a presse aux nouveaux médias (1979) ; Éloge du grand public. Une théorie critique de la télévision (1991) ; Naissance de l'Europe démocratique (1993) ; Penser la communication (1997) ; Internet et après (1999).

3 No CNRS: diretor do programa Science, technique et société (1980-1985) ; diretor do programa Sciences de la communication (1985-1997) ; diretor do Laboratoire commmunication et politique (1988-2000) ; diretor da revista Hermès (CNRS-Éd.), desde a sua criação em 1988.

4 N.T. DEA e Terceiros ciclos equivalem ao nosso mestrado e doutorado respectivamente.

\section{Referências}

ADORNO, Theodoro. L'industrie culturelle. Communications, 1963.

ANG, K. \& G.. Politics and Television; Chicago: Quadrangle, 1968.

BARTHES, Roland. Mythologies. Paris: Le Seuil, 1957.

BOUGNOUX, Daniel. Sciences de l'information et de la communication. Paris: Larousse, 1993.

CANETTI, Elias. Masse et puissance. (trad.) Paris: Gallimard, 1996.

CASTELLS, Manuel. La société em réseaux. Paris: Fayard, 1988.

CAZENEUVE, Jean. La société de l'ubiquité. Paris: Denoël, 1972.

ELIAS, Norbert. La société des individus. Paris: Fayard, 1991.

ELLUL, Jacques. La technique ou l'enjeu du siècle. Paris: Economica, 1980.

FRIEDMANN, Georges. Ces merveilleux instruments. Paris: Denoël-Gonthier, 1979.

GLICK, Ira \& LÉVY, Sidney. Living with Television. Chicago: Aldine, 1962.

HABERMAS, Jürgen. L'espace public. Paris: Payot,1978.

HOGGART, Richard. La culture du pauvre. Étude sur le style de vie des classes populaires em Anglaterre. Paris: Éd. De Minuit, 1970.

JEANNENEY, Jean-Noël. Une histoire des médias. Paris: Le Seuil, 1996.

KATZ, Elihu \& LAZARSFELD, Paul F.. Personnel Influence: The Part Played by the People in the Flow of Mass Communication. Glencoe: The Free Press,1955. 
LAZAR, Judith. Sociologie de la communication de masse. Paris: Colin, 1991.

LYOTARD, Jean-François. La condition post-moderne. Paris: Éd. de Minuit: 1979.

MCQUAlL, Denis. Mass Communication Theory. Londres: Sage,1983.

MARCUSE, Herbert. L'Homme unidimensionnel; étude sur lidéologie de la société industrielle avancée. Paris: Éd. de Minuit, 1968.

MATTELART, Armand. L'invention de la communication. Paris: La Découverte, 1994.

MORIN, Edgard. L'esprit du temps, essai sur la culture de masse. Paris: Le Seuil, 1962.

MUMFORD, Lewis. Le mythe de la machine. Paris: Fayard, 1973.

RAYNAUD, Philippe; Rials, Stephane. Dictionnaire de la philosophie politique. Paris: PUF, 1996.

SCHAEFFER, Pierre. Machines à communiquer. Paris: Le Seuil, 1970.

SCLESSINGER, Philip. Media, State, Nation, Political Violence and Collective Identites. Londres: Sage. 1991.

SCHRAMM, Wilbur. Mass Communication. Urbana: University of Illinois Press, 1960.

SFEZ, Lucien. Dictionnaire critique de la communication, Paris: PUF, 1993.

SILLS, David L.. Internationnal Encyclopedia of Social Sciences, New York: Marmittan, 1968.

SIMONDON, Gilbert. Du mode d'existence des objets techniques. Paris: Aubier,1969.

TARDE, Gabriel. L'opinion de la foule. Paris, PUF: 1989.

WOLTON, Dominique. Penser la communication. Paris: Flammarion, 1999.

nouveaux médias. Paris: Flammarion, 2000.

Internet et après? Une théorie critique des 